Journal of Physical Science, Vol. 32(3), 89-101, 2021

\title{
The Physical and Mechanical Properties of Corn-based Bioplastic Films with Different Starch and Glycerol Content
}

\author{
Nur Nadia Nasir* and Siti Amira Othman \\ Department of Physics and Chemistry, Faculty of Applied Sciences and Technology, \\ Universiti Tun Hussein Onn Malaysia, 84600 Pagoh, Johor, Malaysia \\ *Corresponding author: hw180041@siswa.uthm.edu.my
}

Published online: 25 November 2021

To cite this article: Nasir, N. N. \& Othman, S. A. (2021). The physical and mechanical properties of corn-based bioplastic films with different starch and glycerol content. J. Phys. Sci., 32(3), 89-101. https://doi.org/10.21315/jps2021.32.3.7

To link to this article: https://doi.org/10.21315/jps2021.32.3.7

\begin{abstract}
Petroleum-based plastics have had a long history with varied materials and applications. However, the major drawback with these plastics is their harmful impact on the environment. Poor disposal management of these plastics have ultimately affected humans. Therefore, starch-based bioplastics have been widely used because of their renewability, sustainability and cost-effectiveness. This work investigated the effect of different concentrations of corn starch $(10 \%, 15 \%$, and $20 \% \mathrm{w} / \mathrm{w}$ of distilled water) and glycerol $(20 \%, 30 \%$, and $40 \% \mathrm{w} / \mathrm{v}$ of corn starch) on the properties of corn-based bioplastic films. Particularly, mechanical (tensile strength, Young's modulus and elongation at break) and physical (water absorption rate and moisture content) properties were investigated. These films were prepared by the solvent casting method. It was demonstrated that the addition of $30 \%$ glycerol produced mechanical properties closest to the standard value, while films with a composition of $15 \%$ of corn starch had the most optimised value. Meanwhile, 20\% glycerol and $20 \%$ corn starch produced a film with high strength and stiffness but lacked flexibility. Higher concentrations of starch and glycerol produced the highest moisture and water absorption rate. This was due to the highly hydrophilic nature of both corn starch and glycerol. However, the concentration of glycerol needs to be adjusted based on the intended use of the film. In conclusion, the concentration of corn starch and glycerol produced slightly different outcomes. Thus, the properties and application of the cornbased bioplastic films can be maximised by optimising the concentration of corn starch and glycerol.
\end{abstract}

Keywords: corn-based bioplastic, glycerol, mechanical properties, moisture content, water absorption 


\section{INTRODUCTION}

Increase in awareness on the harmful impact of petroleum plastic towards the environment and ultimately humans, have gained the interest of the community towards bioplastics. The current bioplastics in the market are polylactic acid (PLA)-based and oxo-degradable plastics. ${ }^{1}$ However, both of these plastics require a controlled environment to break down. Hence, starch-based bioplastics were introduced.

Starch is an abundant, renewable and sustainable raw material. ${ }^{2}$ However, the major drawbacks of starch-based bioplastics are their brittleness and hydrophilicity, which limits their applications. ${ }^{3}$ To reduce brittleness and stiffness, while improving flexibility, plasticisers are added to these bioplastics. Starch-based bioplastics produced without plasticisers boast low elasticity, are very stiff and have high tensile strength. Glycerol is one of the commonly used plasticisers. It is non-hazardous and safe for food manufacturing. ${ }^{4}$

Thus, several factors affect the properties of starch-based films. The first factor is the type of starch used. The amylose and amylopectin content of the starch influences the film's properties. Regular corn starch is composed of $26 \%$ to $30 \%$ of amylose and $70 \%$ to $74 \%$ of amylopectin. ${ }^{5}$ A high amylose content typically produces films with better properties.

Another factor is the concentration of the plasticiser. Basiak et al. stated that the concentration of plasticiser needs to be optimised to produce starch-based bioplastics, which are mechanically durable and with appropriate flexibility. ${ }^{6}$ According to Thakur et al., the most optimised concentration of plasticisers is between $20 \%$ and $40 \% .{ }^{4}$ Munthoub and Rahman further reported that the water absorption of starch-based films increased with a higher content of glycerol, while a concentration of glycerol higher than $35 \%$ led to decreased tensile strength. ${ }^{7}$ Meanwhile, Sofiah et al. recorded that when the concentration of glycerol was increased and banana peel was added, the mechanical properties of corn-based films decreased. ${ }^{8}$

In this study, corn-based bioplastic films are produced at different concentrations of starch $(10 \%, 15 \%$, and $20 \%)$ and glycerol $(20 \%, 30 \%$, and $40 \%)$. The effect of the concentration of starch and glycerol on the physical and mechanical properties of the corn-based bioplastic films are investigated. 


\section{EXPERIMENTAL}

\subsection{Materials}

Corn starch was purchased from Emory laboratory reagents (Selangor, Malaysia). Glycerol was supplied by HmbG Chemicals (Hamburg, Germany) and acted as a plasticiser. Acetic acid with 5\% acidity was purchased from Kraft Heinz Foods Company (Selangor, Malaysia). Distilled water was used in the formulation as well.

\subsection{Preparation of Film}

The film (corn-based bioplastic) solution was prepared by mixing $100 \mathrm{ml}$ of distilled water and $(10 \%, 15 \%$ and $20 \% \mathrm{w} / \mathrm{w}$ of distilled water) corn starch. Next, glycerol $(20 \%, 30 \%$ and $40 \% \mathrm{w} / \mathrm{v}$ of starch) was added as a plasticiser. Lastly, $5 \mathrm{ml}$ of acetic acid at $5 \% \mathrm{w} / \mathrm{w}$ was added into the solution. Acetic acid was used to break some of the polymer branches of amylopectin. A heavily branched polymer hinders the formation of a good plastic. The film solution was then heated to $75^{\circ} \mathrm{C}$ under constant stirring using a magnetic stirrer to obtain starch gelatinisation. Manual stirring was continued until the solution had become viscous and transparent. The resulting solution was poured into a petri dish, that acted as a casting plate and dried in an air-conditioned room $\left(25 \pm 1{ }^{\circ} \mathrm{C}\right)$ for $72 \mathrm{~h}$ on a flat surface, to ensure a consistent film thickness. This drying process employed was the solvent casting method. ${ }^{9,10}$ Film thickness was measured using a digital micrometre at five different areas of each film sample. The average film thickness for each sample is presented in Table 1. Table 2 shows the ratio of corn starch and glycerol content used. For each characterisation test, three samples were analysed, and the average results were considered.

Table 1: Average film thickness.

\begin{tabular}{lc}
\hline Sample & Average film thickness $(\mathrm{mm})$ \\
\hline A & 0.25 \\
B & 0.40 \\
C & 0.45 \\
D & 0.25 \\
E & 0.40 \\
F & 0.45 \\
G & 0.30 \\
H & 0.40 \\
I & 0.45 \\
\hline
\end{tabular}


Table 2: Ratio of corn starch and glycerol content.

\begin{tabular}{lcc}
\hline Sample & Corn starch (w/w of distilled water) $\%$ & Glycerol (w/v of corn starch) $\%$ \\
\hline A & 10 & 20 \\
B & 15 & 20 \\
C & 20 & 20 \\
D & 10 & 30 \\
E & 15 & 30 \\
F & 20 & 30 \\
G & 10 & 40 \\
H & 15 & 40 \\
I & 20 & 40 \\
\hline
\end{tabular}

\subsection{Characterisation}

\subsubsection{Mechanical properties}

Mechanical properties of the films were determined using a Universal Testing Machine (UTHM, Johor, Malaysia), which includes tensile strength, elongation at break and Young's modulus. Each sample was cut into $100 \mathrm{~mm} \times 15 \mathrm{~mm}$ and clamped between the grips at the initial gauge separation length of $60 \mathrm{~mm}$. Tests were run with a crosshead speed of $0.5 \mathrm{~mm} / \mathrm{sec}$. This method followed the standard test method for tensile properties of thin plastic sheeting (ASTM D882-02).

\subsubsection{Physical properties}

The films were weighed before and after conditioning in an oven for $24 \mathrm{~h}$ or until a constant weight was obtained at $50^{\circ} \mathrm{C}$. Moisture content in the film was calculated using the following equation:

Moisture content $(\%)=[($ Weight before - Weight after $) /$ Weight before $] \times 100 \%$

By using the standard test method for water absorption of plastic (ASTM D570), the film samples were cut into $50.8 \mathrm{~mm}$ in diameter. Conditioning was performed in an oven for $24 \mathrm{~h}\left(50 \pm 3^{\circ} \mathrm{C}\right)$. Film samples were then weighed (conditioning weight) using a digital weighing scale, before being immersed in water for $24 \mathrm{~h}$ at a temperature of $23 \pm 1^{\circ} \mathrm{C}$. The film samples were then cloth dried and weighed (wet weight). Films were re-conditioned for the same duration and temperature as stated earlier and re-weighed (reconditioning weight). Water absorption was calculated using the equation below: 
Increase in weight $(\%)=[$ (Wet weight - Conditioning weight $) /$ Conditioning weight] $\times 100 \%$

Soluble matter loss $(\%)=[($ Conditioning weight - Reconditioning weight $) /$ Conditioning weight $] \times 100 \%$

Water absorption $(\%)=$ Increase in weight $(\%)+$ Soluble matter loss $(\%)$

\section{RESULTS AND DISCUSSION}

\subsection{Mechanical Properties}

\subsubsection{Tensile strength}

Based on Figure 1, as the concentration of starch increased, tensile strength also increased. The highest tensile strength at $1.28 \pm 0.10 \mathrm{MPa}, 0.86 \pm 0.21 \mathrm{MPa}$, and $0.54 \pm 0.12 \mathrm{MPa}$ was produced by the highest concentration of starch, with samples $\mathrm{C}, \mathrm{F}$, and I, respectively. This outcome agreed with an earlier report by Abdullah et al. in which the highest concentration of starch $(35 \%)$ exhibited the highest tensile strength $(2.57 \mathrm{MPa}) .{ }^{11}$ Ragadhita et al. further reported that corn-based films with $10 \%$ concentration of corn starch and glycerol, possessed poor tensile strength at $0.5 \mathrm{MPa} .^{12}$

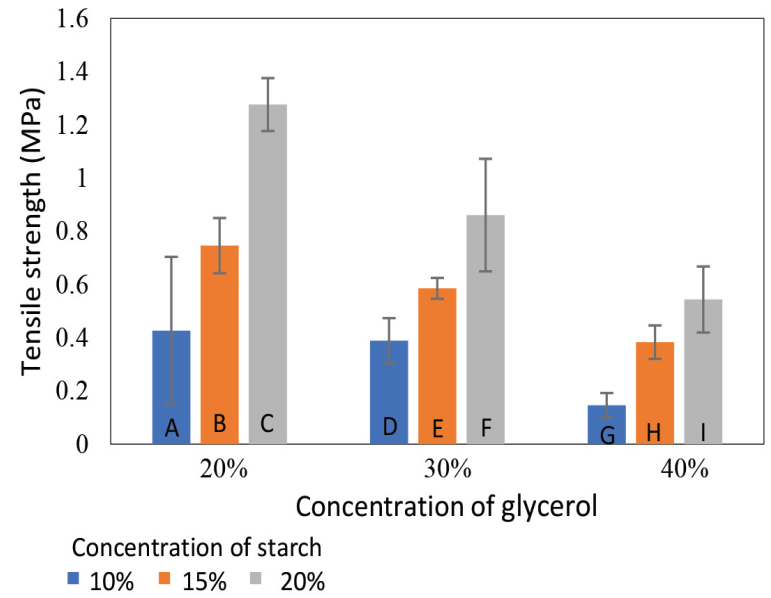

Figure 1: Tensile strength of corn-based bioplastic films with various corn starch and glycerol concentrations. 
In this study, films with concentrations of $10 \%$ corn starch and $20 \%$ glycerol (sample A) recorded a tensile strength of $0.43 \pm 0.2 \mathrm{MPa}$. This finding implies that the strong hydrogen bonds formed by the intermolecular interactions between starch-starch, are more dominant than the interactions between starch-glycerol. ${ }^{13}$ In addition, samples $\mathrm{G}, \mathrm{H}$, and I with the highest concentration of glycerol, had the lowest tensile strength at $0.15 \pm 0.05 \mathrm{MPa}, 0.38 \pm 0.06 \mathrm{MPa}$, and $0.54 \pm 0.12 \mathrm{MPa}$, respectively. Thus, increase in the concentration of glycerol led to the reduction in tensile strength. This data supports the finding by Thakur et al., Basiak et al., and Farahnaky et al. , $, 6,14^{2}$

When glycerol content increases, the intermolecular interaction of glycerol-starch became more dominant than those of starch-starch. Thus, the functional properties of the bioplastics were altered by reducing the intermolecular interaction and increasing the mobility of polymer chains. ${ }^{14}$ Additionally, reduction of the hydrogen bonds in the films, led to an increase in flexibility, which made the films softer and with reduced tensile strength. ${ }^{13}$

\subsubsection{Elongation at break}

Figure 2 shows that the elongation at break contradicted the data on tensile strength. It was discovered that increasing the concentration of starch caused a reduction of elongation of break. Similar studies in the past have reported the same outcome. ${ }^{13,15}$ This might be due to weak interactions between starch molecules and a reduction in the cohesive force of the polymer chains. ${ }^{15}$ On the other hand, as the concentration of glycerol increased, the elongation at break increased. This is due to the increased mobility of the polymer chain that led to an increased elasticity of the material. ${ }^{16}$

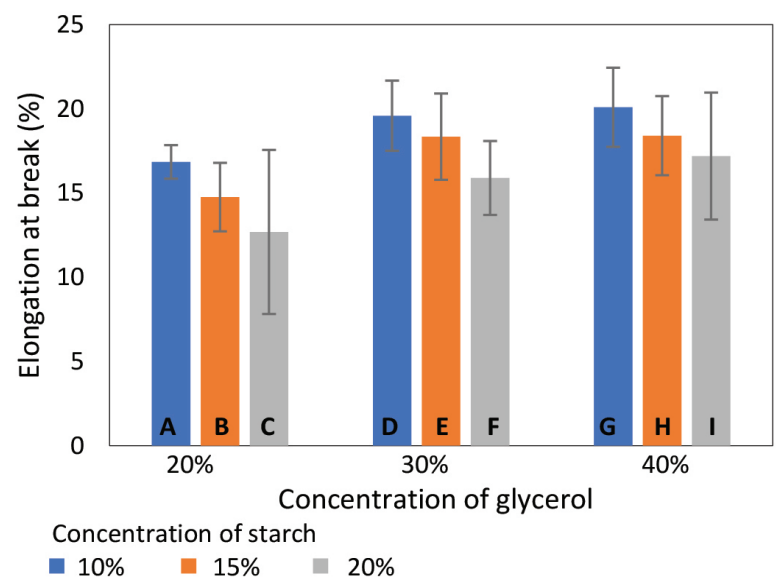

Figure 2: Elongation at break of corn-based bioplastic films with various corn starch and glycerol concentrations. 
Glycerol increases elongation at break by forming hydrogen bonds between the hydroxyl groups in the starch molecules with the glycerol molecules. The presence of glycerol further reduces the interaction between starch molecules (cohesion). ${ }^{17,18}$ This is supported by a previous study by Kuruvila et al. ${ }^{19}$ As the concentration of glycerol was increased at a concentration of $10 \%, 15 \%, 20 \%$, and $25 \%$, the elongation at break of potato-based film also increased. ${ }^{19}$ In further comparison to this study, the potato-based films recorded an elongation at break value of $10 \%$ with $20 \%$ of glycerol, while this corn-based film had a value range of $12 \%$ to $17 \%$. Thus, this was about a $2 \%$ to $7 \%$ increment of elongation at break value.

\subsubsection{Young's modulus}

As reflected in Figure 3, the Young's modulus increased when the concentration of starch increased. Previous studies have also observed that the higher the concentration of starch and the lower the concentration of plasticiser, the higher the material's stiffness. ${ }^{13,20}$ According to Santana et al., increase of the Young's modulus was due to a filler effect promoted by the starch inclusion in the blends, in which starch granules acted as a reinforcement. ${ }^{21}$ Furthermore, an anti-plasticiser effect was seen in the films with $20 \%$ concentration of glycerol. This effect is characterised by ruptures and the non-formation of a continuous matrix. As the plasticiser molecules increased above the critical value, anti-plasticisation occurred. In addition, glycerol is strong enough to reduce internal hydrogen bonds. This causes the increase of distances between intermolecular particles. ${ }^{22,23}$ Figure 3 shows that glycerol helps to significantly increase Young's modulus in the formulations. Glycerol molecules can disrupt starch compactness, decrease the interaction of hydrogen and increase the mobility of polymers. ${ }^{24}$ The changes that have occurred in the starch microstructures further encourage the entry of glycerol into the starch matrix. ${ }^{25}$ The same finding was obtained by Munthoub and Rahman, when the concentration of glycerol increased, the Young's modulus value was found to be decreased. ${ }^{7}$ The Young's modulus result is also correlated with tensile strength. 


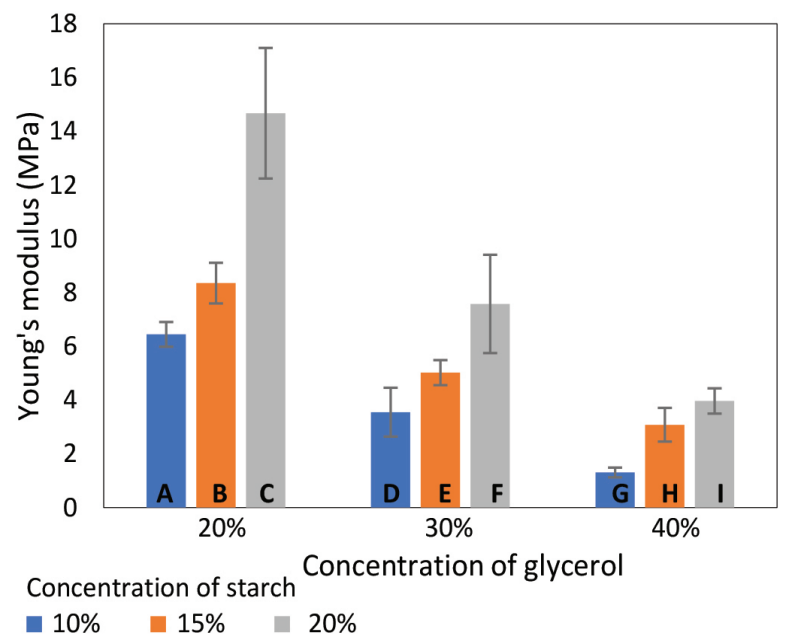

Figure 3: Young's modulus of corn-based bioplastic films with various corn starch and glycerol concentrations.

Table 3 shows the mechanical properties of corn-based bioplastics. Films with the composition of $15 \%$ corn starch had the most optimised result compared to $10 \%$ and $20 \%$ corn starch. Additionally, films with $30 \%$ glycerol (samples D, E, and F) had the most promising mechanical properties, due to the result obtained is the closest to the standard value where a tensile strength of 1-10 $\mathrm{MPa}$, an elongation at break at 10\%-20\%, and a Young's modulus at $2.72 \mathrm{MPa} .{ }^{12}$ Since the mechanical properties for the moderate grade of bioplastics did not reach that of the standard values, an additional filler material must be applied to improve the mechanical properties.

Table 3: Mechanical properties of corn-based bioplastics.

\begin{tabular}{llll}
\hline Sample & Tensile strength $(\mathrm{MPa})$ & Elongation at break (\%) & Young's modulus (MPa) \\
\hline A & $0.43 \pm 0.20$ & $16.85 \pm 1.00$ & $6.45 \pm 0.46$ \\
B & $0.75 \pm 0.10$ & $14.76 \pm 2.03$ & $8.35 \pm 0.76$ \\
C & $1.28 \pm 0.10$ & $12.69 \pm 4.87$ & $14.67 \pm 2.43$ \\
D & $0.39 \pm 0.08$ & $19.59 \pm 2.08$ & $3.55 \pm 0.91$ \\
E & $0.59 \pm 0.04$ & $18.35 \pm 2.56$ & $5.02 \pm 0.47$ \\
F & $0.86 \pm 0.21$ & $15.89 \pm 2.19$ & $7.58 \pm 1.83$ \\
G & $0.15 \pm 0.05$ & $20.09 \pm 2.35$ & $1.31 \pm 0.18$ \\
H & $0.38 \pm 0.06$ & $18.40 \pm 2.35$ & $3.08 \pm 0.63$ \\
I & $0.54 \pm 0.12$ & $17.19 \pm 3.77$ & $3.96 \pm 0.47$ \\
\hline
\end{tabular}




\subsection{Physical Properties}

\subsubsection{Water absorption}

The increase in the percentage of water absorption with respect to glycerol and corn starch indicates that both are highly hydrophilic. It was demonstrated that $20 \%$ and $10 \%$ of starch concentrations had the highest and lowest percentage of water absorption, respectively. Similarly, previous studies have also found that a high concentration of starch increased water absorption. ${ }^{15,26}$ Naturally, the hydrophilic compound would increase the water absorption of the film..$^{18}$ There is the presence of hydroxyl in starch molecules and it is still capable to interact with water, which resulted in increasing water absorption. ${ }^{21}$ During the gelatinisation process, ruptured starch granules occur and made water diffusion easier. ${ }^{26}$ The highly hydrophilic nature of starch and its high sensitivity to moisture causes water to easily move into the amorphous region of starch during immersion.

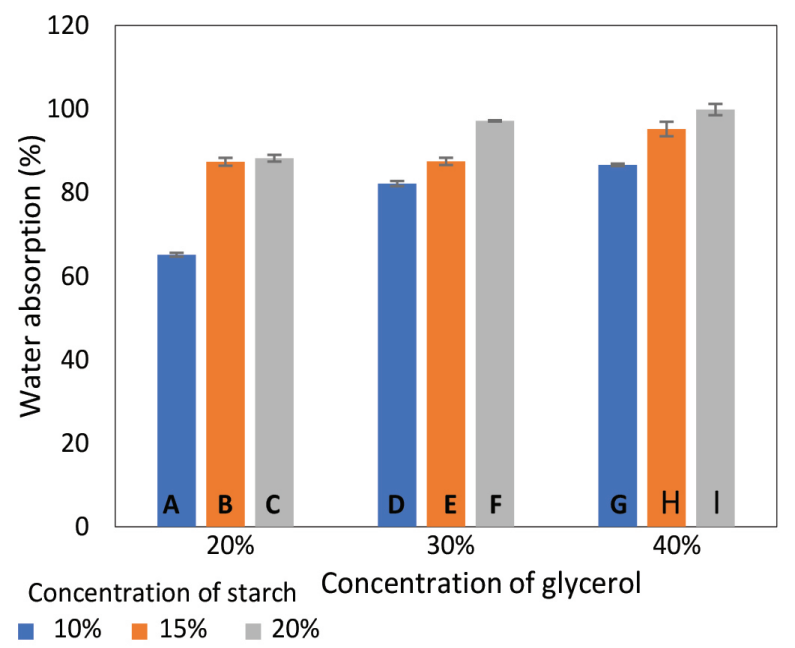

Figure 4: Water absorption of corn-based bioplastic films with glycerol plasticiser.

Apart from the interaction between water molecules and hydroxyl groups in the structure of starch, the plasticisation of glycerol is also a significant factor in water absorption. Water absorption increases as the concentration of glycerol increases. Based on Figure 4, $40 \%$ of glycerol concentration had the highest water absorption and $20 \%$ of glycerol had the lowest water absorption. These data corroborated with that of Ibrahim et al., whereby increasing the concentration of glycerol from $25 \%$ to $55 \%$ significantly increased the water absorption rate of corn starch-based films. ${ }^{27}$ This is due to the water-soluble nature of glycerol and that it is naturally hygroscopic. 
Furthermore, glycerol is known as a hydrophilic low molecular carbohydrate, with the ability to absorb water. However, the absorption depended on the number of hydroxyl groups present and the structure's molecular weight. ${ }^{28}$ Glycerol molecules have three carbons on their backbone and one hydroxyl group on each carbon, causing them to attach to the most amount of water, corresponding to their weight. Thus, the water absorption of the film increases as the volume of hydroxyl group concentration increases. As shown in Figure 4, the overall result of water absorption was very high for all samples.

\subsubsection{Moisture content}

As shown in Figure 5, the highest concentration of glycerol and starch at $40 \%$ and $20 \%$, respectively, had the highest moisture content. This trend was similar to that of water absorption. According to Ibrahim et al., regardless of the plasticiser type, the addition of plasticiser increased the thickness and moisture content of all films ${ }^{27}$ Hazrol et al. also reported that moisture content was significantly increased as the concentration of plasticisers rose from $30 \%$ to $60 \%{ }^{29}$ In general, increasing the concentration of plasticisers caused starch-based films to become more hydrophilic. Some studies also found that adding more plasticiser to hydrocolloid films increased their moisture content. ${ }^{8,27,28}$ Due to the hydrophilic properties of both glycerol and corn starch, the solubility and moisture content of the films were increased. ${ }^{24}$ In the current study, Sample A had the lowest moisture content at $9 \%$, meanwhile both samples $\mathrm{F}$ and I had the highest moisture content value of $21 \%$. This was due to the evaporation of moisture from the samples. All samples exhibited the same high susceptibility to the humid atmosphere and were unable to maintain a constant humidity content in conditions with varying relative humidity. ${ }^{30}$

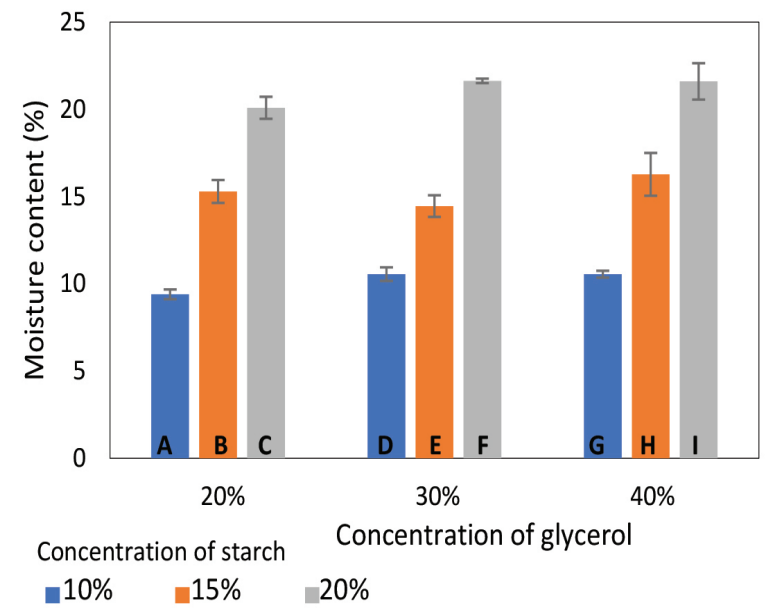

Figure 5: Moisture content of corn-based bioplastic films with glycerol as a plasticiser. 


\section{CONCLUSION}

In the current study, it can be ascertained that the physical and mechanical properties of corn-based bioplastic films have been successfully optimised with various concentrations of corn starch and glycerol. A film with desirable physical and mechanical properties can be produced with manipulation of the concentration of corn starch and glycerol. In comparison to $20 \%$ and $40 \%$ concentrations of glycerol, corn-based bioplastic films with 30\% glycerol had the most ideal mechanical properties. This was based on the result of the measured parameters closest to the standard value. Films with the composition of $15 \%$ corn starch had the most optimised result compared to $10 \%$ and $20 \%$ corn starch concentrations. Films made with the least amount of glycerol (20\%) and the most amount of corn starch $(20 \%)$, had a high tensile strength and stiffness but lacked flexibility. The water absorption rate result revealed that the film with the lowest concentration of corn starch and glycerol had a favourable water absorption rate. On the contrary, moisture content was significantly increased as the concentration of corn starch and glycerol increased. The properties and application of corn-based bioplastics can be maximised with the optimisation of corn starch and glycerol's content. Thus, with the aim of having a targeted application for the bioplastics, the concentration of starch and glycerol can be adjusted. Furthermore, the addition of fillers is needed to enhance the properties of corn-based bioplastics.

\section{ACKNOWLEDGEMENTS}

The authors would like to thank the Faculty of Applied Sciences and Technology, Universiti Tun Hussein Onn Malaysia for the facilities provided and the financial support, a research grant (H417) that made the research possible.

\section{REFERENCES}

1. Finzi-Quintão, C. M., Novack, K. M. \& Bernardes-Silva, A. C. (2016). Identification of biodegradable and oxo-biodegradable plastic bags samples composition. Macromol. Sympo., 367(1), 9-17. https://doi.org/10.1002/masy.201500156

2. Gadhave, R. V. et al. (2018). Starch based bio-plastics: The future of sustainable packaging. Open J. Polym. Chem., 8(2), 21-33. https://doi.org/10.4236/ ojpchem.2018.82003

3. Shafik, S. S., Kawakib, J. M. \& Mohanad, I. K. (2014). Preparation of PVA/corn starch blend films and studying the influence of gamma irradiation on mechanical properties. Int. J. Mater. Sci. Appl., 3(2), 25-28. 
4. Thakur, R. et al. (2019). Starch-based films: Major factors affecting their properties. Int. J. Biol. Macromol., 132, 1079-1089. https://doi.org/10.1016/j. ijbiomac.2019.03.190

5. Podshivalov, A. et al. (2017). Gelatin/potato starch edible biocomposite films: Correlation between morphology and physical properties. Carbohydr. Polym., 157, 1162-1172. https://doi.org/10.1016/j.carbpol.2016.10.079

6. Basiak, E., Lenart, A. \& Debeaufort, F. (2018). How glycerol and water contents affect the structural and functional properties of starch-based edible films. Polym., 10(4), 412. https://doi.org/10.3390/polym10040412

7. Munthoub, D. I. \& Rahman, W. A. W. A. (2011). Tensile and water absorption properties of biodegradable composites derived from cassava skin/polyvinyl alcohol with glycerol as plasticizer. Sains Malays., 40(7), 713-718.

8. Sofiah, et al. (2019). Mechanical properties of bioplastics product from Musa paradisica formatypica concentrate with plasticizer variables. J. Phys.: Conf. Ser., 1167, 012048. https://doi.org/10.1088/1742-6596/1167/1/012048

9. Othman, S. H. et al. (2019). Tapioca starch films reinforced with microcrystalline cellulose for potential food packaging application. Food. Sci. Technol., 39(3), 605612. https://doi.org/10.1590/fst.36017

10. Karki, S. et al. (2016). Thin films as an emerging platform for drug delivery. Asian J. Pharm. Sci., 11(5), 559-574. https://doi.org/10.1016/j.ajps.2016.05.004

11. Abdullah, A. H. D. et al. (2019). Fabrication and characterization of sweet potato starch-based bioplastics plasticized with glycerol. J. Biol. Sci., 19(1), 57-64. https://doi.org/10.3923/jbs.2019.57.64

12. Ragadhita, R. et al. (2020). Mechanical and biodegradation properties of cornstarch-based bioplastic material. Mater. Phys. Mech., 44(3), 380-391. http:// doi.org/10.18720/MPM.4432020_9

13. Abdullah, A. H. D., Oceu, D. P. \& Sugandi, W.W. (2019). Effects of starchglycerol concentration ratio on mechanical and thermal properties of cassava starch-based bioplastics. Jurnal Sains Materi Indonesia, 20(4), 162-167. https:// doi.org/10.17146/jsmi.2019.20.4.5505

14. Farahnaky, A., Saberi, B. \& Majzoobi, M. (2013). Effect of glycerol on physical and mechanical properties of wheat starch edible films. J. Texture Stud., 44(3), 176-186. https://doi.org/10.1111/jtxs.12007

15. Sapei, L. et al. (2015). The effect of banana starch concentration on the properties of chitosan-starch bioplastics. J. Chem. Pharm. Res., 7(9S), 101-105.

16. Amin, M. R., Chowdhury, M. A. \& Kowser, M. A. (2019). Characterization and performance analysis of composite bioplastics synthesized using titanium dioxide nanoparticles with corn starch. Heliyon, 5(8), 1-12. https://doi.org/10.1016/j. heliyon.2019.e02009

17. Lusiana, S. W. et al. (2019). Bioplastic properties of sago-PVA starch with glycerol and sorbitol plasticizers. J. Phys.: Conf. Ser., 1351: 012102. https://doi.org/10.1088/1742-6596/1351/1/012102

18. Marichelvam, M. K., Jawaid, M. \& Asim, M. (2019). Corn and rice starchbased bio-plastics as alternative packaging materials. Fibers, 7(4), 32. https://doi.org/10.3390/fib7040032 
19. Kuruvila, M. E., Sudhakaran, N. \& Madhu, V. (2018). Starch-based plastic: Strength, degradation in soil and water absorbance ability. Int. J. Adv. Sci. Res. Manag., 3(11), 155-158.

20. Wald, M. J., Considine, J. M. \& Turner, K. T. (2011). Measuring the elastic modulus of soft thin films on substrates. In: Proulx T. (eds). Conference Proceedings of the Society for Experimental Mechanics Series. New York: Springer. 741-747. https:// doi.org/10.1007/978-1-4419-9792-0_105

21. Santana, R. F. et al. (2018). Characterization of starch-based bioplastics from jackfruit seed plasticized with glycerol. J. Food. Sci. Tech., 55(1), 278-286. https:// doi.org/10.1007/s13197-017-2936-6

22. Issa, A. T. et al. (2018). Sweet potato starch-based nanocomposites: Development, characterization, and biodegradability. Starch, 70(7-8), 1700273. https://doi.org/10.1002/star.201700273

23. Ballesteros-Mártinez, L., Pérez-Cervera, C. \& Andrade-Pizarro, R. (2020). Effect of glycerol and sorbitol concentrations on mechanical, optical, and barrier properties of sweet potato starch film. NFS. J., 20, 1-9. https://doi.org/10.1016/j. nfs.2020.06.002

24. Sanyang, M. L. et al. (2016). Effect of plasticizer type and concentration on physical properties of biodegradable films based on sugar palm (Arenga pinnata) starch for food packaging. J. Food. Sci. Tech., 53(1), 326-36. https://doi.org/10.1007/ s13197-015-2009-7

25. Zakaria, N. H., Muhammad, N. \& Abdullah, M. M. A. B. (2018). Effect of glycerol content on mechanical, microstructure and physical properties of thermoplastic potato starch film. AIP Conf. Proc., 2030(1). https://doi.org/10.1063/1.5066871

26. Sujuthi, R. A. F. M. \& Liew, K. C. (2016). Properties of bioplastic sheets made from different types of starch incorporated with recycled newspaper pulp. Trans. Sci. Tech., 3, 257-264.

27. Ibrahim, M. I. J. et al. (2019). Physical, thermal, morphological, and tensile properties of cornstarch-based films as affected by different plasticizers. Int. J. Food Prop., 22(1), 925-941. https://doi.org/10.1080/10942912.2019.1618324

28. Sultan, N. F. K. \& Johari, W. L. W. (2017). The development of banana peel/ corn starch bioplastic film: A preliminary study. Bioremediat. Sci. Tech. Res., 5(1), 12-17.

29. Hazrol, M. D. et al. (2021). Corn starch (Zea mays) biopolymer plastic reaction in combination with sorbitol and glycerol. Polymers, 13(2), 242. https://doi.org/10.3390/polym13020242

30. Abral, H. \& Hartono, J. (2017). Moisture absorption of starch based biocomposites reinforced with water hyacinth fibers. IOP Conf. Ser.: Mater. Sci. Eng., 213, 012035. https://doi.org/10.1088/1757-899X/213/1/012035 